\title{
Rastreio do câncer do colo do útero: limites etários, periodicidade e exame ideal: revisão da evidência recente e comparação com o indicador de desempenho avaliado em Portugal
}

\author{
Cervical cancer screening: target age bracket, screening frequency \\ and screening method: review of recent evidence \\ and comparison with the Portuguese performance indicator
}

\author{
Bárbara Castro ${ }^{1}$ \\ Daniela Pinheiro Ribeiro ${ }^{1}$ \\ Joana Oliveira ${ }^{1}$ \\ Miguel Basto Pereira ${ }^{2}$ \\ Jaime Correia de Sousa ${ }^{2}$ \\ John Yaphe ${ }^{2}$
}

\footnotetext{
${ }^{1}$ Unidade de Saúde Familiar Manuel Rocha Peixoto. Largo Paulo Orósio $2^{\circ}$ andar. 4.700-036 Braga Minho Portugal. bcusf1@gmail.com ${ }^{2}$ Instituto de Ciências da Vida e da Saúde (ICVS), Escola de Ciências da Saúde, Universidade do Minho e ICVS/3B's Laboratório Associado.
}

Abstract The scope of this review was to assess the strength of evidence of Portuguese performance indicators on Cervical Cancer screening: (1) age group of the women that should be screened for cervical cancer; (2) frequency of screening; and (3) the best method for screening. The following MeSH terms were searched: vaginal smears, age groups, periodicity, methods, uterine cervical cancer. Articles not reflecting the study objectives or not available in English, Portuguese or Spanish were excluded. The SORT classification was used to rate the articles selected. Of the 197 articles found, 9 that met all study criteria were selected for inclusion in this review. These included 1 systematic review, 1 randomized controlled clinical trial, 2 retrospective studies and 5 clinical guidelines. The authors also chose to include 4 clinical guidelines and two systematic reviews relevant to the Portuguese population even though they did not appear in the initial search of the literature. The studies suggest screening women between the ages of 21 to 25 years and 65 years of age, once every three years using conventional cytology. There is still controversy regarding the three objectives of this study (target age bracket, screening frequency and screening method).

Key words Uterine cervical neoplasms, Screening, Vaginal smears, Age brackets, Periodicity
Resumo Esta revisão teve por objetivo avaliar a força de evidência do indicador de desempenho português relativo ao rastreio do Câncer do Colo do Útero (CCU): (1) limites etários das mulheres da população geral que o devem realizar, a (2) periodicidade com que deve ser realizado e (3) qual o melhor exame de rastreio. Foram pesquisados os seguintes termos MeSH: vaginal smears, age groups, periodicity, methods, uterine cervical cancer. Foram excluídos os artigos que não abordavam o objetivo da investigação ou que não fossem redigidos em Inglês, Português ou Espanhol. Para interpretar os artigos selecionados foi utilizada a classificação SORT. Foram encontrados 197 artigos, dos quais seleccionados 9: 1 revisão sistemática (RS), 1 estudo clínico controlado aleatorizado, 2 estudos observacionais retrospectivos e 5 normas de orientação clínica (NOC). Os autores optaram por incluir nesta revisão mais 4 NOCs e 2 RSs por considerarem ser relevantes para a população Portuguesa, apesar de não resultarem da pesquisa efectuada. Os estudos sugerem realização do rastreio entre os 21 e 25 até aos 65 anos, com uma periodicidade trienal usando a citologia convencional. Existe ainda controvérsia no que toca aos 3 objetivos deste artigo (limites etários, frequência e método).

Palavras-chave Neoplasias do colo do útero, Rastreio, Esfregaço vaginal, Grupos etários, Periodicidade 


\section{Introdução}

De acordo com dados de 2008 da Organização Mundial de Saúde (OMS), o câncer do colo do útero (CCU) é o $2^{\circ}$ câncer mais comum em mulheres a nível mundial, com cerca de 500.000 novos casos e 250.000 mortes a cada ano $^{1-4}$. Em Portugal, o CCU é o $6^{\circ}$ câncer mais comum 4 , e o $3^{\circ}$ câncer mais frequente entre as mulheres 5 .

A infeção por vírus do papiloma humano (HPV) é uma das infeções de transmissão sexual mais comum a nível mundial. $O$ risco de infeção por HPV ao longo da vida é de 50 a $80 \%$ em ambos os sexos, a infeção é um fator necessário para o desenvolvimento CCU, mas não independente. Existem mais de 200 estirpes de HPV identificadas, mas apenas algumas são oncogénicas ${ }^{6,7}$ (as de maior risco são 16 e 18). A grande maioria das mulheres elimina o vírus ao fim de 1-2 anos, noutras a infeção pode persistir, originando lesões mais graves designadas por pré-cancerosas e cerca de $3 \%$ pode desenvolver lesão maligna ${ }^{6-9}$. O CCU é geralmente uma doença de evolução lenta, a progressão das lesões pré-malignas pode durar até 10 a $20 \operatorname{anos}^{10}$. O pico de incidência do CCU é aos 51 anos $^{11}$ e é raro em mulheres jovens (1-2 casos por milhão entre os 15 e 19 anos $)^{12}$.

De todos os tumores malignos, o CCU é o que consegue ser controlado mais eficazmente pelo rastreio ${ }^{13}$.

A avaliação citológica das células do colo do útero foi introduzida por George Papanicolaou em 1940, sendo provavelmente a técnica de rastreio oncológico mais utilizada em países desenvolvidos $^{12,14}$. Apesar deste teste ter tido um sucesso evidente na redução da incidência e mortalidade do CCU, tem as suas limitações, particularmente, nos resultados falso negativo. Para tentar colmatar estas limitações têm sido feitos esforços no sentido de desenvolver tecnologias que aumentem principalmente a sensibilidade deste método de rastreio, como por exemplo: a citologia em meio líquido e o teste do DNA do HPV ${ }^{14,15}$.

$\mathrm{O}$ indicador de desempenho português, que diz respeito ao rastreio do $\mathrm{CCU}$, avalia mulheres entre os 25 e 64 anos que realizaram uma colpocitologia nos últimos 3 anos $^{16,17}$. Foi definido pela primeira vez no documento "Indicadores de desempenho para as Unidades de Saúde Familiar" publicado em 2006 pelo Ministério da Saúde, e não sofreu qualquer alteração desde que foi criado até à atualidade ${ }^{16}$.

É, portanto, necessária uma revisão da evidência científica e das múltiplas normas de orientação clínica/consensos recentes que orientam os planos de rastreio e prevenção oncológica do $\mathrm{CCU}$, em diversos contextos internacionais, sobre a relação custo-benefício de cada um dos componentes deste indicador.

Os objetivos deste artigo são avaliar a força de recomendação deste indicador, procurando: (1) analisar em que idades as mulheres da população geral devem realizar o rastreio, (2) a periodicidade com que deve ser realizado e (3) qual o melhor exame de rastreio.

\section{Métodos}

Para realizar esta revisão da evidência científica, os autores selecionaram os termos MeSH na página da Pubmed que consideraram mais adequados: vaginal smears, age groups, periodicity, methods, uterine cervical cancer.

Foram pesquisadas Normas de Orientação Clínicas, Revisões Sistemáticas e Meta-análises, bem como estudos originais publicados desde 2005 (uma vez que as referências mais recentes que são utilizadas para justificar o indicador atualmente em vigor são anteriores a 2005) até Março de 2012, nas seguintes bases de dados, selecionadas pelo painel de especialistas em Medicina Geral e Familiar, como sendo as bases mais reputadas: National Guideline Clearinghouse (NGC), Canadian Medical Association Practice Guidelines Infobase (CMA), Cochrane, Database of Abstracts of Reviews of Effectiveness (DARE), Evidence Based Medicine Online, Science Direct, Springerlink e na PubMed.

Os artigos excluídos dos resultados foram: os repetidos, os que não correspondiam aos objetivos da revisão, os com amostras com características específicas (e.g. risco elevado de CCU, imunodeprimidas, rastreio secundário) ou baseados em modelos teóricos, e os que não fossem redigidos em Inglês, Português ou Espanhol. A seleção foi realizada com base na leitura do abstract e artigo, de forma comparada, pelas duas primeiras autoras desta revisão.

Os autores optaram por incluir algumas publicações/normas, através da pesquisa de artigos relacionados ou contidos nas referências dos anteriores, que respeitavam os critérios de inclusão e exclusão acima descritos e considerados pertinentes para este estudo.

Para a classificação do nível de evidência utilizou-se a taxonomia Strength of Recommendation Taxonomy, SORT, sendo esta uma das taxonomias mais utilizadas na publicação de revisões baseadas na evidência no domínio da medicina e 
particularmente na área dos Cuidados de Saúde Primários. Esta é uma classificação simples que agrupa os estudos em 3 níveis de evidência de onde derivam 3 graus de força de recomendação. O nível de evidência é atribuído consoante a qualidade e consistência dos estudos, do nível 3 ao nível 1, de melhor qualidade. O SORT inclui 3 graus de força de recomendação $(A, B, C)$ baseada na qualidade das evidências disponíveis. A recomendação A baseia-se em evidência de boa qualidade e orientada para o doente, é a que tem maior força ${ }^{18}$.

\section{Resultados}

O total da pesquisa resultou em 197 artigos, de entre os quais foram selecionados inicialmente 29 que pareciam enquadrar-se no âmbito desta revisão. Após uma análise mais cuidada, destes foram excluídos 20: 4 artigos repetidos e 16 que não cumpriam os critérios de inclusão.

Obtiveram-se 9 artigos relevantes, em língua inglesa: 5 NOC, das quais 2 com nível de evidência 1, com metodologia bem definida e graus de recomendação com base na evidência encontrada e 3 com nível de evidência 3 que se basearam em consensos de peritos; e 3 estudos originais: 1 estudo clínico controlado aleatorizado, 2 estudos observacionais retrospetivos; e 1 Revisão Sistemática (RS) de estudos não aleatorizados, estes com nível de evidência 3 devido a resultados orientados para a doença e não para o doente.

Como já referido, foram incluídos outros artigos não resultantes da pesquisa direta, sendo eles: 4 NOC e 2 RS, devido à importância para a população portuguesa, a publicação recente ou nível de evidência elevado: Consensos da Sociedade Portuguesa de Ginecologia de 2011, Guidelines Europeias de 2010 e da Organização Mundial de Saúde (OMS) de 2006, as recomendações da United States Preventive Services Task Force (USPSTF), com base nas quais o nosso indicador foi elaborado, e 2 RS elaboradas pela USPSTF de 2011.

Apresentam-se nos Quadros 1, 2 e 3 os resultados encontrados.

Não foram encontrados estudos controlados aleatorizados com resultados orientados para o doente, como a diminuição da mortalidade por CCU.

Em relação ao objetivo (1), a idade de início é mais controversa do que a idade de término. Os estudos com evidência mais elevada: a NOC da American College of Obstetricians and Gynecolo- gists $(A C O G)^{19}$ que utiliza a escala de recomendação da USPST; a NOC, do Institute for Clinical Systems Improvement ${ }^{20}$ (ICSI) que usa uma escala de recomendação própria sobreponível à da USPSTF e as recomendações da própria USPS$T F^{21}$, indicam o início do rastreio aos 21 anos independentemente da idade de início da atividade sexual (recomendação A). Não está recomendado iniciar rastreio antes dos 21 anos devido à baixa incidência de câncer nestas idades, elevada prevalência de infeção por HPV transitórias e lesões do colo que regridem espontaneamente originando elevado número de falsos positivos e tratamento desnecessário com possíveis riscos/consequências evitáveis. A OMS ${ }^{22}$ e as Guidelines Europeias $^{23}$ apontam para um início mais tardio entre os 25 e os 30 anos, justificando que o CCU é raro antes dos 30 anos e não é custo-eficaz rastrear em idades mais jovens. Apesar disso a NOC de consensos, Michigan Quality Improvement Consortium $^{22}$,que recomenda início aos 18 anos e 1 estudo observacional retrospetivo de Sigurdsson e Sigvaldason ${ }^{24}$, recomenda início aos 20 anos, estes estudos defendem que a idade de início da atividade sexual é cada vez mais precoce, e que a história natural do CCU possa ser mais curta em mulheres mais jovens, por isso o atraso do início do rastreio aumentaria a sua taxa de incidência. Por outro lado, outro estudo observacional retrospetivo encontrado, realizado no Reino Unido, com base numa amostra 4012 mulheres, conclui que a incidência CCU não diminui aos 25-29 anos realizando o rastreio aos 22-24 anos $^{25}$.

Em relação à idade para descontinuar o rastreio quase todos os estudos analisados são concordantes, recomendando os 65 anos (recomendação A), alguns prolongam o intervalo até aos 70 anos como é o caso da $A C O G^{19}$ e da $I C S I^{20}$. As indicações Europeias ${ }^{13}$ antecipam dos 60 aos 65 anos, no entanto todos os estudos referem a necessidade de 3 resultados anteriores consecutivos normais ou sem alterações nos últimos 10 anos (recomendação A). A ineficiência do rastreio após os 65 anos deve-se ao facto de o risco de CCU ser menor, é necessário maior número de citologias para detetar lesões pré-malignas, e aumentam as causas concorrentes de morte. Todavia se falarmos em termos de rastreio oportunístico e não de base populacional o aumento da esperança média de vida impede o estabelecimento de uma idade limite para o fim deste tipo de rastreio $^{26}$.

Relativamente ao objetivo (2), os estudos que avaliam as diferentes periodicidades são maioritariamente baseados em modelos teóricos, com 
Quadro 1. NOC, abordagem segundo os 3 objetivos desta revisão: (1) idades das mulheres da população geral que devem realizar o rastreio do CCU (2) a periodicidade com que esse exame deve ser realizado (3) qual o melhor exame de rastreio.

\begin{tabular}{|c|c|c|}
\hline \multicolumn{3}{|c|}{ Normas de orientação clínica } \\
\hline Referência & Conclusões & Recomendação \\
\hline $\begin{array}{l}\text { Institute for Clinical } \\
\text { Systems } \\
\text { Improvement } \\
\text { (ICSI) }^{20} \\
\text { Preventive Services } \\
\text { for adults } \\
\text { Setembro } 2010\end{array}$ & $\begin{array}{l}\text { (1) Iniciar rastreio } \geq 21 \text { anos, independentemente da idade } \\
\text { de início da atividade sexual } \\
\text { Terminar aos } 65-70 \text { anos, se citologias normais nos últimos } \\
10 \text { anos } \\
\text { (2) } 2-2 \text { anos entre } 21-29 \text { anos } \\
3-3 \text { anos } \geq 30 \text { anos, após } 3 \text { citologias normais } \\
\text { (3) Citologia convencional e em meio líquido métodos } \\
\text { equivalentes } \\
\text { Citologia associada a teste DNA HPV é a forma de rastreio } \\
\text { mais sensível e específico, mas não há benefício em fazer os } \\
\text { dois }\end{array}$ & A \\
\hline $\begin{array}{l}\text { American College } \\
\text { of Obstetricians } \\
\text { and Gynecologists } \\
\text { Cervical Cytology } \\
\text { Screening }{ }^{19} \\
\text { Dezembro } 2009\end{array}$ & $\begin{array}{l}\text { (1) Iniciar rastreio } \geq 21 \text { anos } \\
\text { Terminar aos } 65-70 \text { anos, se citologias normais nos últimos } \\
10 \text { anos } \\
\text { (2) } 2-2 \text { anos entre } 21-29 \text { anos } \\
3-3 \text { anos } \geq 30 \text { anos, após } 3 \text { citologias consecutivas normais } \\
\text { (3) Citologia convencional e em meio líquido métodos } \\
\text { equivalentes citologia associada a teste DNA HPV só são } \\
\text { apropriados para mulheres com }>30 \text { anos }\end{array}$ & A \\
\hline $\begin{array}{l}\text { American Academy } \\
\text { of Family Physicians } \\
\text { Summary of } \\
\text { recommended } \\
\text { actions for clinical } \\
\text { preventive services }^{27} \\
\text { Maio } 2011\end{array}$ & (2) Recomenda rastreio de 3 em 3 anos & $\mathrm{C}$ \\
\hline $\begin{array}{l}2 \text { Normas da } \\
\text { Michigan Quality } \\
\text { Improvement } \\
\text { Consortium } \\
\text { Adult preventive } \\
\text { services } \\
\text { Setembro } 2008 \\
\text { (2 artigos: } 1 \text { com } \\
\text { população alvo } \\
18-49 \text { anos e outro } \\
\text { com população alvo } \\
\geq 50 \text { anos) }\end{array}$ & $\begin{array}{l}\text { (1) Iniciar rastreio } \geq 18 \text { anos } \\
\text { Descontinuar a partir do } 65 \text { anos } \\
\text { (2) } 3-3 \text { anos (desde que não seja de alto risco) } \\
\text { (3) Citologia convencional }\end{array}$ & $\mathrm{C}$ \\
\hline
\end{tabular}

base na história natural da doença, os quais foram excluídos dos resultados. Os estudos epidemiológicos têm demonstrado diminuição da incidência de mortalidade por CCU até $80 \%$ com periodicidade de 3-5 anos ${ }^{22}$. A periodicidade parece variar em muitos dos estudos consoante a faixa etária, com períodos mais curtos nas idades mais jovens e períodos mais alargados nas idades mais avançadas, e consoante o método utilizado.

Os estudos com maior nível de evidência recomendam que entre os 21 e os 29 anos haja 
Quadro 2. Estudos originais e revisão sistemática, abordagem segundo os 3 objetivos desta revisão: (1) idades das mulheres da população geral devem realizar o rastreio do câncer do colo do útero (2) a periodicidade com que esse exame deve ser realizado (3) qual o melhor método de rastreio.

\begin{tabular}{|c|c|c|c|}
\hline \multicolumn{4}{|c|}{ Estudos originais e revisão sistemática } \\
\hline Estudo & Tipo de estudo e metodologia & Conclusões & $\begin{array}{l}\text { Nível de } \\
\text { evidência }\end{array}$ \\
\hline $\begin{array}{l}\text { ARTISTIC: a } \\
\text { randomised trial of } \\
\text { humanpapillomavirus } \\
\text { (HPV) testing in } \\
\text { primarycervical } \\
\text { screening. } \\
\text { Kitchener et al. } .^{29}\end{array}$ & $\begin{array}{l}\text { Estudo clínico aleatorizado } \\
\text { controlado Objetivo: avaliar a } \\
\text { associação da citologia em meio } \\
\text { líquido com teste do DNA do HPV } \\
\text { na redução da incidência de CIN3 } \\
\text { População estudada: mulheres entre } \\
\text { os } 20 \text { - } 64 \text { anos. } \\
\text { Compara a citologia versus citologia } \\
\text { associada a DNA do HPV em } 2 \\
\text { períodos de rastreio com } 3 \text { anos de } \\
\text { intervalo }\end{array}$ & $\begin{array}{l}\text { (3) Teste do DNA do HPV } \\
\text { não trouxe eficácia adicional } \\
\text { significativa à citologia Não } \\
\text { é custo-eficaz rastrear com } \\
\text { citologia e DNA do HPV } \\
\text { combinados }\end{array}$ & 3 \\
\hline $\begin{array}{l}\text { Is it rational to start } \\
\text { population-based } \\
\text { cervical cancer } \\
\text { screening at or soon } \\
\text { after age } 20 \text { ? Analysis } \\
\text { of time trends in } \\
\text { preinvasive and } \\
\text { invasive diseases. } \\
\text { Sigurdsson e } \\
\text { Sigvaldason }^{24}\end{array}$ & $\begin{array}{l}\text { Estudo observacional retrospetivo } \\
\text { Objetivo: avaliar o efeito de rastrear } \\
\text { no grupo etário dos } 20-34 \text { anos } \\
\text { analisando a evolução da doença } \\
\text { pré-invasiva e invasiva, na Finlândia } \\
\text { entre } 1995 \text { e } 2003\end{array}$ & $\begin{array}{l}(1)(2) \text { Recomenda rastreio } \\
\text { depois dos } 20 \text { anos cada } \\
2-3 \text { anos }\end{array}$ & 3 \\
\hline $\begin{array}{l}\text { Effectiveness of } \\
\text { cervical screening } \\
\text { with age: population } \\
\text { based case control } \\
\text { study of prospectively } \\
\text { recorded data. } \\
\text { Sasieni et al. }\end{array}$ & $\begin{array}{l}\text { Estudo observacional retrospetivo } \\
\text { Objetivo: avaliar a eficácia do } \\
\text { rastreio na incidência do CCU, } \\
\text { particularmente em idades }<25 \\
\text { anos }\end{array}$ & $\begin{array}{l}\text { (1) Não existe evidência que } \\
\text { o rastreio nas mulheres entre } \\
\text { os } 22-24 \text { anos reduza a } \\
\text { incidência de CCU aos } 25-29 \\
\text { anos (OR 1.11) }\end{array}$ & 3 \\
\hline $\begin{array}{l}\text { Diagnostic accuracy } \\
\text { of human } \\
\text { papillomavirus } \\
\text { testing in primary } \\
\text { cervicalscreening: a } \\
\text { systematic review } \\
\text { and meta-analysis of } \\
\text { non-randomized } \\
\text { studies. } \\
\text { Koliopoulos el al. }{ }^{30}\end{array}$ & $\begin{array}{l}\text { Revisão sistemática } \\
\text { Objetivo: Comparar o teste de DNA } \\
\text { HPV com a citologia na capacidade } \\
\text { de diagnosticar uma lesão intra- } \\
\text { epitelial de alto grau no rastreio } \\
\text { primário de CCU }\end{array}$ & $\begin{array}{l}\text { (3) Teste do HPV vs } \\
\text { Citologia: mais sensível mas } \\
\text { menos específico } \\
\text { Teste do HPV associado à } \\
\text { citologia: é o método mais } \\
\text { sensível de todos e o menos } \\
\text { específico. } \\
\text { Diminuição da incidência ou } \\
\text { mortalidade por CCU com } \\
\text { teste HPV vs citologia ainda } \\
\text { não foi demonstrada }\end{array}$ & 3 \\
\hline
\end{tabular}

periodicidade bienal e a partir dos 30 anos trienal (recomendação A), exceto a $U S P S T F^{21}$ que recomenda realização de 3 em 3 anos em qualquer faixa etária elegível para rastreio ou de 5 em 5 anos a partir dos 30 anos mas com citologia associada à pesquisa de DNA HPV (recomendação 
Quadro 3. NOC/RS, não resultantes da pesquisa direta, abordagem segundo os 3 objetivos desta revisão: (1) idades das mulheres da população geral devem realizar o rastreio do cancer do colo do útero (2) a periodicidade com que esse exame deve ser realizado (3) qual o melhor método de rastreio.

\begin{tabular}{|c|c|c|}
\hline \multicolumn{3}{|c|}{ Outros estudos incluídos } \\
\hline Referência & Conclusões & $\begin{array}{l}\text { Nível evidência } \\
\text { Recomendação }\end{array}$ \\
\hline $\begin{array}{l}\text { Sociedade Portuguesa } \\
\text { de Ginecologia } \\
\text { Consenso sobre } \\
\text { infeção HPV e lesões } \\
\text { intraepiteliais do } \\
\text { colo, vagina e vulva }{ }^{26} \\
\text { Maio de } 2011\end{array}$ & $\begin{array}{l}\text { (1) Iniciar rastreio } \geq 21 \text { anos ou } 3 \text { anos após início da } \\
\text { atividade sexual. } \\
\text { Terminar rastreio aos } 65 \text { anos com } 3 \text { últimas citologias } \\
\text { normais } \\
\text { (2) Intervalos entre } 3-5 \text { anos } \\
\text { (3) Citologia em meio líquido e teste DNA do HPV são } \\
\text { caros e sem benefícios em relação à citologia convencional }\end{array}$ & $\mathrm{C}$ \\
\hline $\begin{array}{l}\text { Guidelines europeias }{ }^{13} \\
2010\end{array}$ & $\begin{array}{l}\text { (1) Iniciar rastreio entre } 25-30 \text { anos até aos } 65 \text { anos após } 3 \\
\text { citologias consecutivas normais } \\
\text { (2) Periodicidade entre } 3-5 \text { anos } \\
\text { (3) Citologia convencional }\end{array}$ & $\mathrm{C}$ \\
\hline $\begin{array}{l}\text { USPSTF }^{21} \text { (última } \\
\text { atualização 2012) }\end{array}$ & $\begin{array}{l}\text { (1) Iniciar rastreio } \geq 21 \text { anos } \\
\text { Terminar aos } 65 \text { anos (após } 3 \text { citologias consecutivas } \\
\text { normais nos últimos } 10 \text { anos) } \\
\text { (2)(3) Periodicidade: } 3-3 \text { anos se citologia convencional / } \\
\text { 5-5 anos a partir dos } 30 \text { anos com citologia + DNA HPV } \\
\text { (se mulher preferir alargar o intervalo de rastreio) }\end{array}$ & A \\
\hline $\begin{array}{l}\text { USPSTF (RS) } \\
\text { Screening for } \\
\text { Cervical Cancer: a } \\
\text { Systematic evidence } \\
\text { review for } \\
\text { U.S.P.S.T.F. } \\
\text { Maio 2011 }\end{array}$ & $\begin{array}{l}\text { (1) Iniciar rastreio } \geq 21 \text { anos } \\
\text { (3) Citologia convencional, quando comparada com } \\
\text { citologia meio líquido, não difere em sensibilidade, } \\
\text { especificidade ou taxa relativa de deteção de CIN. }\end{array}$ & 3 \\
\hline $\begin{array}{l}\text { USPSTF (RS) } \\
\text { Liquid-based cytology } \\
\text { and Human } \\
\text { Papillomavirus } \\
\text { testing to screen for } \\
\text { Cervical Cancer - } \\
\text { Systematic review for } \\
\text { U.S.P.S.T.F. } \\
\text { Outubro } 2011\end{array}$ & $\begin{array}{l}\text { (3) Citologia convencional quando comparada com } \\
\text { citologia meio líquido, não difere em sensibilidade, } \\
\text { especificidade ou taxa relativa de deteção de CIN. } \\
\text { Teste do DNA do HPV é mais sensível do que a citologia, } \\
\text { mas tem uma especificidade mais reduzida. Está em } \\
\text { investigação como possível método de triagem, seguido de } \\
\text { citologia subsequente apenas nos positivos. }\end{array}$ & 3 \\
\hline $\mathrm{WHO}^{22}$ & $\begin{array}{l}\text { (1) } \geq 30 \text { anos, mais cedo só se fatores de risco } \\
\text { Até aos } 65 \text { anos, se duas últimas citologias normais } \\
\text { (2) Periodicidade: entre os } 25-49 \text { anos de } 3-3 \text { anos; }>50 \\
\text { anos de } 5-5 \text { anos } \\
\text { (3) Citologia convencional. }\end{array}$ & $\mathrm{C}$ \\
\hline
\end{tabular}

A). Algumas normas com menor evidência, mas com grande importância para Portugal: as Guidelines Europeias ${ }^{13}$ e as orientações da $\mathrm{OMS}^{22}$, bem como os Consensos da Sociedade Portu- guesa de Ginecologia ${ }^{26}$ recomendam periodicidade mais alargada: até aos 49 anos trienal e a partir dos 50 anos de 5 em 5 anos (recomendação C). A maioria dos CCU ocorrem em mulheres 
que nunca foram rastreadas ou que o foram há mais de 5 anos $^{21}$.

Analisando o objetivo (3), a citologia convencional é um método utilizado há vários anos com eficácia comprovada, conseguindo uma redução muito acentuada na incidência de CCU, no entanto apresenta 2 grandes limitações: um número elevado de falsos negativos e resultados insatisfatórios. Para tentar ultrapassar estas desvantagens têm surgido novas tecnologias como a citologia em meio líquido e a deteção do DNA do HPV.

Dos estudos analisados todos concluem que a citologia em meio liquido tem sensibilidade e especificidade equivalente à convencional (recomendação A) e um custo superior, no entanto apresenta menor taxa de resultados insatisfatórios e possibilidade de diferentes análises com uma só colheita (pesquisa de HPV). Concluem também que a associação dos 2 métodos, citologia em meio líquido e pesquisa de HPV, não é uma abordagem custo-eficaz, não parecendo existir vantagem nesta associação (recomendação B), exceto o alargamento do período de rastreio para 5 anos em mulheres com mais de 30 anos $^{21}$.

O teste de HPV é mais sensível e, contudo, menos específico. A recente revisão sistemática da USPSTF, assim como o estudo ARTISTIC consideram-no uma estratégia apelativa como $1^{\mathrm{a}} \mathrm{li}$ nha, se associada sequencialmente à citologia quando o resultado for positivo, diminuindo assim os falsos positivos. No entanto a evidência é escassa e não foi demonstrada a diminuição da incidência e mortalidade por CCU com o teste HPV versus citologia.

\section{Conclusão}

Comparando o indicador que avalia atualmente em Portugal o rastreio do CCU com os estudos analisados podemos concluir que:

(1) em relação à idade de inicio de rastreio mantêm-se algumas controvérsias: os estudos com mais evidência encontrados nesta revisão apontam para o inicio aos 21 anos e nunca antes, independentemente do inicio da atividade sexual (Recomendação A), mais cedo do que é atualmente avaliado em Portugal (25 anos), apesar de existirem normas Europeias que recomendam iniciar entre os 25-30 anos e um estudo retrospetivo que conclui não existir vantagem em rastrear antes dos 25 anos. Os 65 anos são a idade recomendada para finalizar o rastreio (Recomen- dação A). É relativamente uniforme entre todos os estudos, e coincide com o indicador português. No entanto, é de consenso geral que esta descontinuação seja feita apenas se existirem 3 citologias consecutivas negativas ou sem resultados anormais nos últimos 10 anos (Recomendação A), esta premissa não é avaliada pelo indicador.

(2) Relativamente à periodicidade recomendada, existe alguma concordância na periodicidade trienal (Recomendação B), que é a avaliada pelo nosso indicador, seja qual for a faixa etária. No entanto, existem normas com nível de evidência elevado, Europeias e Mundiais, que sugerem intervalos de rastreio diferentes consoante a idade em causa. Entre os 21 e 29 anos, existe controvérsia entre bienal e trienal (Recomendação B), dos 30 aos 49 anos existe concordância na periodicidade trienal (Recomendação A) e a partir dos 50 até aos 65 a frequência recomendada pode ser alargada para 5 em 5 anos (Recomendação C). A USPSTF recentemente atualizou as suas recomendações, e considerou que na faixa etária a partir dos 30 anos a periodicidade de 5 em 5 anos com citologia associada a pesquisa do DNA HPV, era uma alternativa válida à periodicidade trienal com a citologia isolada, se as mulheres preferissem aumentar a periodicidade de rastreio (Recomendação $\mathrm{A}$ ).

(3) Quanto ao método a utilizar, o indicador apenas refere colpocitologia, não especificando se é convencional ou em meio liquido, no entanto, como são exames equivalentes em termos de sensibilidade e especificidade, e tendo a convencional um custo menor deve manter-se este o método de escolha (Recomendação A).

Os autores apontam algumas limitações desta revisão que devem ser tidas em consideração: a pesquisa abrangeu um período reduzido de tempo, artigos publicados desde 2005 e foi restrita a 3 idiomas (português, inglês e espanhol).

É escassa a evidência de boa qualidade nesta área, foram encontrados poucos estudos controlados aleatorizados, existem vários estudos baseados em modelos teóricos e os resultados são orientados para a doença, como a diminuição de deteção de CIN 2 ou 3, e não para a doente como por exemplo a redução da mortalidade por CCU e maior qualidade de vida para a doente.

É necessário continuar a acompanhar os estudos nesta área para adequarmos a nossa prática clínica ao estado da arte. Mantêm-se controvérsias quanto à idade de início do rastreio, quanto ao exame de rastreio, nomeadamente, na possibilidade da pesquisa de HPV ser a $1^{\text {a }}$ linha, e se for positiva, se seguida de citologia, o que poderá tra- 
zer diferentes periodicidades a aplicar. Não deve ser esquecido que o rastreio dentro de alguns anos poderá ser progressivamente menos custo-eficaz porque o risco de desenvolver CCU vai eventualmente diminuir com a vacina do CCU, recentemente introduzida no plano de vacinação nacional. A introdução da vacina também resultou em sugestões para a necessidade de intensificar esforços a nível do rastreio para diminuir ainda mais as mortes por $\mathrm{CCU}^{33}$. É provável que a história natural da doença se altere, terão que se rever as idades ótimas para rastreio que vão variar consoante a imunidade sustentada da vacina.

\section{Colaboradores}

B Castro e DP Ribeiro participaram na concepção e delineamento do artigo, pesquisa bibliográfica, análise e interpretação dos dados, redação do artigo e aprovação final do artigo. J Oliveira, MB Pereira, JC Sousa e Y Yaphe participaram na interpretação dos dados, discussão dos resultados, na revisão crítica do artigo e aprovação final do artigo.

\section{Agradecimentos}

Apoio da Bolsa Condicionada AstroZeneca 


\section{Referências}

1. Scarinci I, Garcia FA, Kobetz E, Partridge EE, Brandt HM, Bell MC, Dignan M, Ma GX, Daye JL, Castle PE. Cervical Cancer Prevention: New Tools and Old Barriers. Cancer 2010; 116(11):2531-2542.

2. Bray F, Jemal A, Grey N, Ferlay J, Forman D. Global Cancer Statistics. Ca Cancer J Clin 2011; 61(2):6990.

3. Mathew A, George PS. Trends in incidence and mortality rates of squamous cell carcinoma and adenocarcinoma of cervix- worldwide. Asian Pac J Cancer Prev 2009; 10(4):645-650.

4. Ferlay J. GLOBOCAN 2008. Cancer Incidence and Mortality Worldwide: IARC Cancer Base N. 10. Lyon, France: International Agency for Research on Cancer; Year. [Internet]. [acessado 2010 ago 17]. Disponível em: http://globocan.iarc.fr.

5. Sociedade Portuguesa de Ginecologia (SPG). Consenso em Patologia Cervico-Vulvovaginal. Coimbra: SPG; 2004.

6. Portugal. Direcção Geral de Saúde. Comissão Técnica de Vacinação (CTV). Vacinação contra infecções por HPV. Porto: CTV; 2008.

7. McLay LA, Foufoulides C, Merrick JR. Using simulation-optimization to construct screening strategies for cervical cancer. Health Care Manag Sci 2010; 13(4):294-318.

8. Apgar BS, Brotzman GL, Spitzer M, Ignatavicius DD. Colposcopy. Principles and Practice. An Integrated Textbook and Atlas. Philadelphia: WB Saunders Co; 2002.

9. Gross GE, Barrasso R. Human Papilloma Virus Infection: a clinical atlas. Berlin: Ed. Ullstein Mosby Gmbh \& Co.; 1997.

10. Frame PS, Frame JS. Determinants of Cancer screening frequency: the example of screening for cervical cancer. J Am Board Fam Pract 1998; 11(2):87-95.

11. Siebert U, Sroczynski G, Hillemanns P, Engel J, Stabenow R, Stegmaier C, Voigt K, Gibis B, Hölzel D, Goldie SJ. The German cervical cancer screening model: development and validation of a decision analytic model for cervical cancer screening in Germany. Europ J Public Health 2006; 16(2):185-192.

12. Uptodate. Sreening for cervical cancer. [Internet]. [acessado 2011 jun 30]. Disponível em: www. Uptodate.com

13. Arbyn M, Anttila A, Jordan J, Ronco G, Schenck U, Segnan N, Wiener H, Herbert A, von Karsa L. European Guidelines for Quality Assurance in Cervical Cancer Screening. Second Edition-Summary Document. Ann Oncol 2010; 21(3):448-458.

14. Safaeian M, Solomon D. Cervical Cancer Prevention - Cervical Screening: Science in Evolution. Obstet Gynecol Clin North Am 2007; 34(4):739.

15. Siebers AG, Klinkhamer PJ, Grefte JM, Massuger LF, Vedder JE, Beijers-Broos A, Bulten J, Arbyn M. Comparison of Liquid-Based Cytology With Conventional Cytology for Detection of Cervical Cancer Precursors - A Randomized Controlled Trial. JAMA 2009; 302(16):1757-1764.

16. Portugal. Ministério da Saúde (MS). Missão para os Cuidados de Saúde Primários. Indicadores de Desempenho para as Unidades de Saúde Familiar. Lisboa: MS; 2006.
17. Portugal. Administração Central do Sistema de Saúde (ACSS). Cuidados de Saúde Primários. Metodologia de Contratualização. Lisboa: ACSS; 2010.

18. Ebbel MH, Siwek J, Weiss BD, Woolf SH, Susman J, Ewigman B, Bowman M.. Strength of Recommendation Taxonomy (SORT): A Patient-Centered Approach to Grading Evidence in the Medical Literature. Am Fam Physician 2004; 69(3):548-555

19. American College of Obstetricians and Gynecologists (ACOG). Cervical Cytology Screening. Washington: ACOG; 2009. (ACOG practice bulletin; no. 109).

20. Institute for Clinical Systems Improvement (ICSI). Preventive Services for adults. Bloomington: ICSI; 2010.

21. U.S. Preventive Services Task Force (USPSTF). Screening for Cervical Cancer, Topic Page. March 2012. [Internet]. [acessado $2014 \mathrm{fev}$ 25]. Disponível em: http://www.uspreventiveservicestaskforce.org/uspstf/ uspscerv.htm

22. World Health Organization (WHO). Comprehensive cervical cancer control. A guide to essential practice. Geneva: WHO; 2006.

23. Michigan Quality Improvement Consortium. Adult preventive services (18-49). Southfield: Michigan Quality Improvement Consortium; 2008.

24. Sigurdsson K, Sigvaldason H. Is it rational to start population-based cervical cancer screening at or soon after age 20? Analysis of time trends in preinvasive and invasive diseases. Eur J Cancer 2007; 43(4):769-744.

25. Sasieni P, Castanon A, Cuzick J. Effectiveness of cervical screening with age: population based case control study of prospectively recorded data. $B M J$ 2009; 339:b2968

26. Sociedade Portuguesa de Ginecologia (SPG). Consenso sobre infecção HPV e lesões intraepiteliais do colo, vagina e vulva. Coimbra: SPG; 2011

27. American Academy of Family Physicians (AAFP). Summary of recommended actions for clinical preventive services. Leawood: AAFP; 2011

28. Michigan Quality Improvement Consortium Adult preventive services $(\geq 50)$. Southfield: Michigan Quality Improvement Consortium; 2008.

29. Kitchener HC, Almonte M, Gilham C, Dowie R, Stoykova B, Sargent A, Roberts C, Desai M, Peto J; ARTISTIC Trial Study Group.. ARTISTIC: a randomized trial of human papillomavirus (HPV) testing in primary cervical screening. Health Technol Assess 2009; 13(51):1-150.

30. Koliopoulos G, Arbyn M, Martin-Hirsch P, Kyrgiou M, Prendiville W, Paraskevaidis E. Diagnostic accuracy of human papillomavirus testing in primary cervicalscreening: A systematic review and metaanalysis of non-randomized studies. Gynecol oncol 2007; 104:232-246.

31. U.S. Preventive Services Task Force (USPSTF). Screening for Cervical Cancer: a Systematic evidence review for U.S.P.S.T.F. Maio 2011. [Internet]. [acessado 2014 fev 25]. Disponível em: https://www.ncbi. nlm.nih.gov/books/NBK66099/ 
32. U.S. Preventive Services Task Force (USPSTF). Liquid-based cytology and Human Papillomavirus testing to screen for Cervical Cancer - Systematic review for U.S.P.S.T.F. Outubro 2011. [Internet]. [acessado 2014 fev 25]. Disponível em: http://www.us preventiveservicestaskforce.org/uspstf11/cervcancer/ cervcancerref.htm

33. Yamamoto AN. Introducing HPV vaccine and scaling up screening procedures to prevent deaths from cervical cancer in Japan: a cost-effectiveness analysis. BJOG 2012; 119(2):177-186.

Artigo apresentado em 10/08/2012

Aprovado em 27/09/2012

Versão final apresentada em 01/10/2012 